REVIEW ARTICLE

\title{
A Comprehensive Review of Embracing the Normality of Rape Culture: Time to Put a Stop to Victim Blaming
}

Shamima Haque Priya, ${ }^{a^{*}}$ Sharmin Haque Prima ${ }^{\mathrm{b}}$

${ }^{a}$ University Guest worker, Center for peace studies (CPS), North South University

Department of Electrical and computer Engineering, North South University

${ }^{b}$ Dens dental clinic, BDS, PGT, MPH

Department of Public health, North South University

*Corresponding Author

\begin{abstract}
Gender discrimination against women is a prevalent issue in Bangladesh, but sometimes it is concealed. Rape cases, also known as "sexual abuse" in many cultures, are a special insidious type of sexual harassment. In other contexts, when you are familiarizing with the lifestyle of women, as a social worker it is likely to see victims of sexual abuse due to a large number of abusive offenders. Global WHO figures suggest that about 1 in $3(35 \%)$ of women around the world endure physical and sexually intimate relationships or non-partner sexual abuse during their lives. Domestic abuse is the most heinous form of violence. Approximately one third (30\%) of all women who have a relationship comment on physical and sexual harassment witnessed by their intimate partner nationwide. This review investigates several peer-reviewed journals and articles that have been developed for the comprehensive understanding of domestic abuse as rape. Still, this issue of rape must be addressed within and outside the scope of domestic violence. More experiments are conducted with a focus for future studies. The major argument of this review is that while raped women are suffering from the permanent effects of psychological and emotional damage, the issue of rape is not the problem of women. It is squarely a man's problem. As a society, victim allegation is preached as a flame, but the issue is with ancestors and older generations' minds and opinions. On a conclusive note, strategies for rape prevention have been discussed. It is crucial to recognize and increasingly teach young children about the effects of sexual harassment and how traditions can be changed to avoid social stigma.
\end{abstract}

Keywords: rape victims, sexual assault, social work, victim-blaming, prevention

\section{Introduction}

In the 1970s, with secondary freedoms for women, the social theory of abuse or rape culture began. Even though this building is quoted as often as possible (Swauger et al., 2013), little effort has been made to validate the construction of this scheme. Scholars primarily describe rape culture as "an 
unavoidable system of perception that maintains or forgive sexual assault in a workable fashion" (Burt, 1980). In an attempt to determine an assault myth's acceptance, Martha Burt (1980) demonstrated the most detailed demonstration of assault culture. This evidence was meant to constitute a society of attack by traditional sexual identity, antagonistic sexual convictions and acceptance of interpersonal savagery (Garcia-Moreno \& Amin, 2019).

In 1995, Burt's show of the harassment society was expanded to encompass misogyny and menaces against women. Besides, they developed recognition of interpersonal falsity to provide a more expansive concept of fallacy. Sexism is linked to abuse and sexual aggressions, since it retains the discomfort of the control between men and women, restricting women's right to get their voices heard both metaphorically in the lack of casualty and reality through neglecting the word "no."

\# The MeToo hashtag was launched on Twitter on 24 October 2017. While the sentence was initiated in 2006 by Tarana Burke from African American women's rights activists, it was frequently used by actress Alyssa Milano as a Twitter hashtag in reply to Hollywood producer Harvey Weinstein's accusations of sexual attack. Milano welcomed members of the public via the \# MeToo hashtag to participate in demonstrating the scope of the sexual harassment epidemic. The hashtag was used 12 million times in the first 24 hours alone to attract both public and media interest (CBS News, 2017).

In compliance with societal conditions and standards, conventional gender-based roles may be defined as roles, duties and desires of men and women (Burt, 1980). Traditionally, the following are examples of gender-based roles: males dominate (e.g. they are taught to be the breadwinners) and women are submissive (e.g. they are supposed to stay home and take care of the house). Men are violent (e.g. aggressive and do not have the ability of self-controlling their temper), and women are passive (e.g. sweet-tempered and satisfying, and need to tolerate all forms of injustice).

Sexism occurs at many stages, both social and institutional, in the United States. People are also discriminated against if they do not adhere to their standards (for example, by breaking the conventional role of women in sex). In addition, in the case of an active female, sexism may take place. In contrast, in the case of a passive male, discrimination can take place. To deter adverse effects and maximize positive reviews, our communities foster gender enforcement (Day, 1995). Moreover, the conviction that men are superior to women is a central component of patriarchy.

Burt (1980) argued that in our society, there was a clear correlation between sex and violence. For starters, raw sexual meetings are frequently portrayed in the media as relaxing. Thus, it is also used to defend sexual harassment and coercive conduct toward women, since women like and love rough sex. In a survey conducted by (Bureau of Justice Statistics ((BJS) - National Crime Victimization Survey (NCVS), 2016), it has been seen that 256,313 women have accepted to be a victim of sexual assaults, and mostly by their intimate partners. In 2014, 634,612 women reported to be victims of sexual violence and domestic violence. Therefore, there is an increase in the number of victims. Furthermore, the study has found that people who are more likely to disclose abusive sexual acts are more likely to tolerate abuse. 


\section{Literature Review}

Rape, which is described as compelled to access the vulva or anus physically or otherwise, exploits the human rights of the victims, which induces permanent health complications (Ferris, 2002). Victims are mostly girls or wives, and may even be men, although rape of a non-partner is exceptionally prevalent in such contexts. Population-based surveys say that up to 37 per cent of men in South Africa has ever raped a woman, and there is no global evidence for rape (Tsai, et al., 2011). The perpetuation of rape is not prosecuted. In one analysis, the authors tried to identify the incidence and related reasons of male perpetration of rape of non-partner women and men and the causes of rape in nine Asia-Pacific locations across six countries: Bangladesh, China, Cambodia, Indonesia, Papua New Guinea, and Sri Lanka (Jewkes, Fulu, Roselli \& Garcia-Moreno, 2013).

Due to insufficient means of assessing sexual harassment, national crime reports, surveys of police activity, arrests, or the scales of imprisonment do not reflect the true nature of the violation. Studies which have prevented these approaches have found that the instances of rape are very high and that sexual harassment has been less severe. (Koss, Gidycz \& Wisniewski, 1987).

South Africa was the first significant population-based rape study published in peer-reviewed literature. While these shortcomings are not restricted, studies from North America and South Africa outlined in a comprehensive review shows that the significant threats of rape involve adverse encounters like mistreatment, relationship and personality distress, social learning and delinquent behaviour. In comparison, the researchers are primarily concerned with prison inmates and high school students (Dartnall \& Jewkes, 2013). Masculinity and sex-inequitable ideologies show the importance of sexual intercourse, including the regulation of controlling women in terms of activities such as physical assault and drug dependency (Malamuth, Sockloskie, Koss \& Tanaka, 1991).

The suspects are much more likely to be women and children, and the perpetrators are identified by the survivor in most circumstances. Children are especially prone to sexual assault, with girls at higher risk, particularly in school and at home. The study has highly exposed the value of primary intervention for childhood violence as a way of addressing childhood vulnerabilities to power, with an improved awareness of the impact of childhood sexual abuse on lateness and victimization (Dartnall \& Jewkes, 2013). The effect of other causes, including the lack of empathy and evidence of genetic influence, has also been discussed (Johansson et al., 2008).

In particular, rape or sexual harassment coexists with other types of intimate partner assault through personal relationships. Victims have also considered being the culprits of sexual assault, and crimes occur mostly intimately (MacLennan, 2013). Similarly, physical assault is less common than sexual abuse. Even during breastfeeding, sexual abuse of a partner is high. In Thailand, Bangladesh and Ethiopia, for example, 28.9, 49.7 and 58.6 per cent of women only reported sexual harassment, with so few mentioning of any other form of sexual harassment (Fulu et al., 2013). Study priorities to clarify the extent of rape or sexual violence occurrence include examining and measuring the prevalence and trends of victims of sexual violence. In various contexts, including women and men, adults, and children, the 
best practices regarding sexual violence and common indicators of various sexual abuses have focused on using various approaches (Dartnall \& Jewkes, 2013).

Forced sex is one of the forms of rape that seems to be more common between girls than boys in adolescence and puberty is a period of the risk of first sex. Two social changes are negligible compared to the wide prevalence of coerced sex, which has occurred between boys (Cáceres et al., 2000). The first is to express modesty by having sex, if you do not even feel comfortable. The second is bullying between boys and older women into sexual acts. The girls have been forced physically in their early teens or adulthood period. It is essential to make both genders understand the meaning of consensual activity, which is not compelled. Therefore, forceful sexual activities can be determined (Sikweyiya \& Jewkes, 2009).

Non-partner rape is now common, but with different instances in different contexts. This community comprises a family member, an outsider, a human with a vision or a knowledge. It is sometimes difficult to compare the figures, as some include rape and attempted rape while others concentrate solely on finished rape (Dartnall \& Jewkes, 2013). The WHO MCS reports that the share of women alleging abuse with an intimate relationship from the age of 15 in the province of Ethiopia ranged under $0.3 \%$ to $11.5 \%$ compared to Tanzania. Again, variations in the prevalence rates reflect the sample type, meanings and context of the research, as well as real structural trends of violence. Prevalence research is of fundamental significance for policymaking and service development, carried out well using well-developed analysis methods and concepts (Pallitto et al., 2012).

Most of the offences include only one suspect, but rape by more than one individual is expected in a particular case. Like in all styles of sexual assault, due to context and meanings, there are significant differences in the frequency identified in surveys of multiple aggressive offenders (Wolfe, 2015). Many gang rape attackers are male. In a gang rape, there is the involvement of more than one rapist which is more violent compared to rape by one particular individual (Fattah \& Camellia, 2017). Predictions on rape based on population-based surveys and analyses of high-income males are between 5.6\%, and 27\% of youth and are based on men disclosing an act matching legal criteria of rape or attempted rape. 24.5 per cent of the US men registered a small population sample of rape legislation or sexual assault act (Dartnall \& Jewkes, 2013).

Physical harassment is typically induced by other abuses like physical, emotional and economical. Few women report sexual harassment alone in cases of intimate partner assault (Devries et al., 2011). Sexual abuse or rape involves many types in classrooms, and in many countries, rape and sexual harassment are frequent with school teachers, other school management and other pupils becoming offenders. Most girls are required to have transactional sexual affairs with teachers because of poverty (Phasha \& Nyokangi, 2012). The effects of sexual assault have physical, reproductive and psychological consequences for wellbeing, which can be fatal, and some can arise unintentionally as a result of violence, such as unhealthy behaviours. Overall, these add to a substantial health burden which should be taken into account by healthcare agencies, governments and NGOs. Immediate treatment should be offered with follow-up plans (Jina \& Thomas, 2013). 
In the context of sexual assault, the health repercussions may be typically grouped into more immediate effects, whereas medium to longer-term impacts arise during the post-sexual violation phase. Implicit health effects may appear well after the violent event, involving unsafe sexual activity. The consequences may also be fatal or non-fatal based on the degree of damage and health issues sexual harassment against women (McFarlane, 2002).

Rape or sexual assault in all societies is widespread in many respects against women, children and men in some cases. There is no rape-free society. Rape frequency varies between contexts. Reasons can include the calculation of sexual violence, interpretations, the embarrassment and humiliation involved, the encouragement of harassment and attack, and cultural values, the importance of women and children in society (Dartnall \& Jewkes, 2013).

\section{Methodology}

For this paper, secondary sources are the main source of information and data. Secondary information is collected from established specialist sources on a wide variety of topics related to rape culture including archival documents, organization, scientific materials and papers. If the secondary data area unit is closely analyzed, the collected secondary data can conclude. The secondary information value depends on the reference data obtained from the first data exploitation after the secondary data assembly.

The overall argument was established by secondary research and followed the necessary solutions. The collected data is information from news stories, publications reviewed by colleagues, CBS news, and several other social media collected by Google Scholar. By matching the sources in the peer-reviewed papers, all the material was checked and confirmed in the original publications.

\section{Possible Solutions and Prevention Methods}

It is not exclusive to women to accuse the perpetrator. Victims are responsible for crimes against humanity as the society conducts a ritual of victim shaming, rather than accusing the perpetrator. Also, when we differentiate class and violence have been declared, old traditions, due to which suffering takes place, it is the unfortunates who are still blamed. However, accusing women of being a prey to rape has a double effect: sexually invading and dis-evaluating women's bodies are destroyed, all because women's bodies are "owned" by one man because it can "carry" children. They are the reproductive means. Women may be the last victim-blaming case in the country. On the body of a female is written the "honour" of a few men, families and cultures ("Eight reasons why victim-blaming needs to stop | BWSS”, 2018). Women's rights are human rights, and we must transfer responsibility towards women who encounter sexual harassment from men, who are violated by men who continuously assaults them. Women who have been beaten to be battered by men, later. Children who are sexually assaulted by adults, who assault them sexually on a regular basis. We must learn together how to become a witness of kindness, and extend our hands towards the victims of sexual abuse (How to Avoid Victim Blaming Harvard Law School Halt, 2015). If they keep treating the unfortunate with their perspective of inequality, we cannot resolve the injustice. 
The society, however, still holds the victim as the one in fault. It is especially true for women, who live among us with a cultural preference which so persistently portrays women as the cause of our demolition, more than that, in the event of rape, shaming them about their upbringing and clothing attire (Ging, 2017). When sticking to the harsh ideals of hyper-masculinity, our culture loves men the most. Men understand that they should still be superior, and they should show the only emotion they are allowed, anger, if their dominance is challenged. Yet by default, they aren't rapists. In a culture of rape that encourages strict standards of masculinity, men are socialized. Without questioning masculinity, merely accusing men buys straight into the system of rape and sells everyone low. It must also be noted that men and boys are also raped and sexually assaulted. The fascination in our society with the beauty of female bodies nourishes the ideology of rape (3 Components of Rape Culture and What You Can Do to Fight Back, 2014). At a young age, girls understand that what matters most about them is how they look, and boys are encouraged above all things to respect this in girls. Women are continually transformed into artifacts due to the relentless emphasis of our society on beauty. The question of making women's bodies into objects is that they are less than human objects. Items have no thoughts or behaviors, or intelligence-there are objects for us to use. When a woman is treated as an object, sexual abuse against her is much easier to commit.

Following sexual harassment, counselling, rehabilitation, and support group programs are beneficial, notably when complicating factors involved with the abuse itself or the rehabilitation process. A few interventions are combating sexual harassment offenders outside the criminal justice system, usually targeted at men accused of male-on-female sexual abuse, which makes up a large number of sexual violence court cases (Schwartz, 1991). A popular reaction of men who commit sexual assault is to deny that they are both accountable and that abusive violence is what they do.

Research has emphasized the value of fostering nurturing to avoid sexual harassment and more robust and more gender-balanced parenting. Health care providers will pursue these challenges in the early years of childhood, adding child sexual exploitation and television attention to violence to the list of conversation subjects and encouraging the use of non-sexist instructional materials (Banyard et al., 2007). Health promotion will include modeling habits and actions in later childhood to resist stereotyping, motivating children to discriminate between positive and negative contact, and strengthening their willingness and trust to take care of their bodies. This intervention would make space for sexual aggression to be addressed.

The concept of victim-blaming, it is necessary to note, is not only widespread in rape. It is the way people in control defend and promote their manipulative and illegal actions, a method that turns people against themselves and their own best interests (Olsen, 2016). Victim guilt primarily exists in class affairs. Whether you are poor, you are deemed to be accountable for your poverty, regardless of sex, ethnicity, age, and sexuality. No society can place your worth; your situation, your poverty and deprivation are your challenges following the dominant society.

Take and talk about your life with passion. Victim guilt is also a pillar of violent culture - a mind-set which gives allegations to a victim of attack instead of the attacker. The sobriety, clothing and 
sexuality of a survivor are meaningless when addressing incidents of sexual assault and blaming the victim (Henry \& Powell, 2014). Instead, in society it is against the notion that men and boys must achieve self-control. They are given the right to abuse and consider sex as their way of exerting their rights on their partner. The society needs to establish zero-tolerance policy in the places where you live, work, study and play, regarding sexual assault and abuse. Leaders must make mostly explicit that they are committed to implementing a policy of zero-tolerance in terms of sexual harassment and that the system must be enforced every day.

Rape culture takes various forms across time and environments. The rape culture goes beyond the narrow notion that a man rapes a woman when she goes home at night. Although no one would argue about the concept of abuse, sexual assault, and sexual harassment are standardized and trivialized by word, behaviour and inaction, leading to a transition road in the embracement of rape culture. Rape culture affects all of us, whether it is in terms of sexuality, colour, religion or age (Women, 2019). Considering this, abandoning rigid gender and sexuality limits the right of an individual to identify and express herself. Rape has been used throughout history as an instrument of conflict and colonialism. It has been used for the destruction, cleansing and genocide of women and their populations. The prevalence and severity of rape and other sexual abuse in Eastern Congo are the worst in the world. A 2010 study showed that in Eastern Congo, 22 percent of men and 30 percent of women reported sexual harassment associated with conflict (Storr, 2011). Despite the peace movement that started in 2003, in the eastern regions of the country, sexual harassment by soldiers from militant forces and the national army continues. Evidence of war rape arose when United Nations forces relocated to areas formerly devastated by war after the peace process began. Gang rape and object-based rape have been confirmed.

Rape is not a funny punchline, ever. Rape jokes delegitimize sexual assault, making it more difficult for women when they are not permitted to speak out about their abuse. It is not appropriate to have humour which normalizes and excuses sexual abuse. Just call it out. The culture of rape is held up by the lack or omission of enforcement of legislation concerned with harassment against women and by patriarchal laws on land possession, marriage, divorce and custody of children (Masser, Viki \& Power, 2006). The offenders must be held responsible for ending the history of abuse. In investigating cases of sexual assault, we acknowledge these acts as crimes and deliver a clear zero-tolerance message. Fight for fairness and responsibility everywhere you see pushback towards the legal impact on offenders.

\section{Conclusion}

This paper has presented an overview where the cultural embrace of rape culture has been established and how the provided solutions would be able to break down the stereotypical thoughts of all generations. Each claim has a personal narrative that helps to form links to the topic and to help the current and potential victims. The younger generations need to continue preaching by telling their story on a forum if their account is not ready for an audience. They can use social networking, or a small meeting with friends and family, maybe a talk show or a radio show, where they can stay anonymous and speak out. It is not enough to put individual survivors of harassment and sexual misconduct to justice. Suppose the problem lies in a group that is obsessed with the shameful acts conducted by men, 
with images of women in various body shapes and sees that particular man, objectifying women. In that case, the answer is to look at the solutions and approach the actions of the individual holistically as a symptom of the culture of violence. As people, everyone has a part to play in stopping rape culture rise because it is possible for society to do more to prevent it.

Alternative approaches are way long delayed since it includes educating young people about sexual intercourse and abuse, and society has not been advocating for alternative sexual paradigms for some time. The sexual ideas that are traditionally open to girls prevent sexual pleasure and satisfaction disproportionately, presenting girls as victims in need of protection against boys' impulses. They are taught to tolerate injustice and to agree to whatever demand is asked by their male partner. It offers women and girls the responsibility to say no and blame boys and men while they "iron out a yes" to remove social and systemic obligations. For girls, the absence of a safe, caring environment is vital. Young boys should be taught about consent, and they should be treated in a way, where they can express themselves and not suppress their feelings.

It is in the hands of the new generation to inspire the world's young revolutionaries. As revolutionaries, activists need to question the myths in the media, on the sidewalks, and at school regarding gender and abusive problems encountered by women, men and children. Let the young children know that their family is a healthy environment for them to portray themselves as they are. And if their family is unable to open up, encourage them to seek psychiatric support. Affirm their choices and show them the importance of consent at a young age.

\section{References}

[1] 3 Components of rape culture and what you can do to fight back. (2014, February 18). Psychology Benefits Society. https://psychologybenefits.org/2014/02/18/3-components-of-rape-culture-andwhat-you-can-do-to-fight-back/

[2] Banyard, V. L., Moynihan, M. M., \& Plante, E. G. (2007). Sexual violence prevention through bystander education: An experimental evaluation. Journal of Community Psychology, 35(4), 463481. https://doi.org/10.1002/jcop.20159

[3] Burt, M. R. (1980). Cultural myths and supports for rape. Journal of Personality and Social Psychology, 38(2), 217-230. https://doi.org/10.1037/0022-3514.38.2.217

[4] Bureau of Justice Statistics (BJS) - National Crime Victimization Survey (NCVS). (2016). Bjs.Gov. https://www.bjs.gov/index.cfm?ty=dcdetail\&iid=245

[5] Cáceres, C. F., Vanoss Marín, B., \& Sid Hudes, E. (2000). Sexual coercion among youth and young adults in Lima, Peru. Journal of Adolescent Health, 27(5), 361-367. https://doi.org/10.1016/s1054-139x(00)00096-3

[6] CBS News. (2017, October 17). More than 12M "Me Too" Facebook posts, comments, reactions in 24 hours. Cbsnews.com. https://www.cbsnews.com/news/metoo-more-than-12-million-facebookposts-comments-reactions-24-hours/ 
[7] Dartnall, E., \& Jewkes, R. (2013). Sexual violence against women: The scope of the problem. Best Practice \& Research Clinical Obstetrics \& Gynaecology, 27(1), 3-13. https://doi.org/10.1016/j.bpobgyn.2012.08.002

[8] Day, K. (1995). Assault prevention as social control: Women and sexual assault prevention on urban college campuses. Journal of Environmental Psychology, 15(4), 261-281. https://doi.org/10.1006/jevp.1995.0024

[9] Devries, K., Watts, C., Yoshihama, M., Kiss, L., Schraiber, L., \& Deyessa, N. et al. (2011). Violence against women is strongly associated with suicide attempts: Evidence from the WHO multicountry study on women's health and domestic violence against women. Social Science \& Medicine, 73(1), 79-86. doi:10.1016/j.socscimed.2011.05.006

[10] Ferris, L. (2002). World report on violence and health. New South Wales Public Health Bulletin, 13(8), 190. https://doi.org/10.1071/nb02075

[11] Fattah, K., \& Camellia, S. (2017). Gender norms and beliefs, and men's violence against women in rural Bangladesh. Journal of Interpersonal Violence, 35(3-4), 771-793. doi: $10.1177 / 0886260517690875$

[12] Fulu, E., Jewkes, R., Roselli, T., \& Garcia-Moreno, C. (2013). Prevalence of and factors associated with male perpetration of intimate partner violence: findings from the UN Multi-country Crosssectional Study on Men and Violence in Asia and the Pacific. The Lancet Global Health, 1(4), e187-e207. https://doi.org/10.1016/s2214-109x(13)70074-3

[13] Garcia-Moreno, C., \& Amin, A. (2019). Violence against women: Where are we 25 years after ICPD and where do we need to go? Sexual and Reproductive Health Matters, 27(1), 346-348. https://doi.org/10.1080/26410397.2019.1676533

[14] Ging, D. (2019) Alphas, betas, and incels: Theorizing the masculinities of the manosphere. Men and Masculinities, 22(4), 638-657. doi:10.1177/1097184X17706401

[15] Henry, N., \& Powell, A. (2014). Preventing sexual violence: Interdisciplinary approaches to overcoming a rape culture. Palgrave Macmillan.

[16] How to Avoid Victim Blaming-Harvard Law School HALT. (2015). Harvard.Edu. https://orgs.law.harvard.edu/halt/how-to-avoid-victim-blaming/

[17] Jewkes, R., Fulu, E., Roselli, T., \& Garcia-Moreno, C. (2013). Prevalence of and factors associated with non-partner rape perpetration: findings from the UN Multi-country Cross-sectional Study on Men and Violence in Asia and the Pacific. The Lancet Global Health, 1(4), e208-e218. doi:10.1016/s2214-109x(13)70069-x

[18] Johansson, A., Santtila, P., Harlaar, N., von der Pahlen, B., Witting, K., \& Ålgars, M. et al. (2008). Genetic effects on male sexual coercion. Aggressive Behavior, 34(2), 190-202. doi: 10.1002/ab.20230 
[19] Jina, R., \& Thomas, L. (2013). Health consequences of sexual violence against women. Best Practice \& Research Clinical Obstetrics \& Gynaecology, 27(1), 15-26. doi:10.1016/j.bpobgyn.2012.08.012

[20] Koss, M., Gidycz, C., \& Wisniewski, N. (1987). The scope of rape: Incidence and prevalence of sexual aggression and victimization in a national sample of higher education students. Journal of Consulting and Clinical Psychology, 55(2), 162-170. doi:10.1037/0022-006x.55.2.162

[21] MacLennan, C. (2013, November 7). Police force fails nz's women ... again. New Zealand Herald. https://www.nzherald.co.nz/nz/catriona-maclennan-police-force-fails-nzs-womenagain/W2JL3QRP635RSW3IDWWZXXBB4E/

[22] Malamuth, N., Sockloskie, R., Koss, M., \& Tanaka, J. (1991). Characteristics of aggressors against women: Testing a model using a national sample of college students. Journal of Consulting and Clinical Psychology, 59(5), 670-681. doi: 10.1037/0022-006x.59.5.670

[23] Masser, B., Viki, G. T., \& Power, C. (2006). Hostile sexism and rape proclivity amongst men. Sex Roles, 54, 565-574. doi:10.1007/s11199-006-9022-2

[24] McFarlane, J. (2002). Abuse during pregnancy and femicide: urgent implications for women's health. Obstetrics \& Gynecology, 100(1), 27-36. doi:10.1016/s0029-7844(02)02054-9

[25] McRobbie, A. (2016). Be Creative: Making a living in the new cultural industries. Polity Press.

[26] Olson, CC. (2016). \#BringBackOurGirls: Digital communities supporting real-world change and influencing mainstream media agendas. Feminist Media Studies, 16(5): 772-787.

[27] Pallitto, C., García-Moreno, C., Jansen, H., Heise, L., Ellsberg, M., \& Watts, C. (2012). Intimate partner violence, abortion, and unintended pregnancy: Results from the WHO multi-country Study on women's health and domestic violence. International Journal of Gynecology \& Obstetrics, 120(1), 3-9. doi: 10.1016/j.ijgo.2012.07.003

[28] Phasha, T., \& Nyokangi, D. (2012). School-based sexual violence among female learners with mild intellectual disability in South Africa. Violence Against Women, 18(3), 309-321. doi: $10.1177 / 1077801212444578$

[29] Schwartz, I. L. (1991). Sexual Violence Against Women: Prevalence, Consequences, Societal Factors, and Prevention. American Journal of Preventive Medicine, 7(6), 363-373. https://doi.org/10.1016/s0749-3797(18)30873-0

[30] Sikweyiya, Y., \& Jewkes, R. (2009). Force and temptation: Contrasting South African men's accounts of coercion into sex by men and women. Culture, Health \& Sexuality, 11(5), 529-541. doi: $10.1080 / 13691050902912783$

[31] Storr, W. (2011, July 16). The rape of men: the darkest secret of war. The Guardian; The Guardian. https://www.theguardian.com/society/2011/jul/17/the-rape-of-men 
[32] Swauger, M., Witham, D. H., \& Shinberg, D. (2013). No stranger in the bushes: The ambiguity of consent and rape in hook up culture. Sex Roles, 68(9-10), 629-633. https://doi.org/10.1007/s11199-012-0251-2

[33] Tsai, A., Leiter, K., Heisler, M., Iacopino, V., Wolfe, W., \& Shannon, K. et al. (2011). Prevalence and correlates of forced sex perpetration and victimization in Botswana and Swaziland. American Journal of Public Health, 101(6), 1068-1074. doi:10.2105/ajph.2010.300060

[34] Villarejo, B. (2017). Misogyny online a short (and Brutish) history. Masculinities and Social Change, 6(3), 304. https://doi.org/10.17583/mcs.2017.3033

[35] Wolfe, L. (2015, September 22). Eight reasons why victim-blaming needs to stop. BWSS. https://www.bwss.org/eight-reasons-why-victim-blaming-needs-to-stop-writers-activists-andsurvivors-speak-out/.

[36] Women, U. N. (2019, November 18). 16 ways you can stand against rape culture. Medium. https://medium.com/@UN_Women/16-ways-you-can-stand-against-rape-culture-88bf12638f12 